\title{
Preparation of High-Surface-Area Zinc Oxide with Ordered Porosity, Different Pore Sizes, and Nanocrystalline Walls
}

\author{
Sebastian Polarz, ${ }^{*[a]}$ Andrey V. Orlov, ${ }^{[a]}$ Ferdi Schüth, ${ }^{[b]}$ and An-Hui Lu ${ }^{[b]}$
}

\begin{abstract}
Transition-metal-oxide materials possessing ordered mesoporosity have recently attracted significant research interest due to their numerous potential applications. Among them, ordered mesoporous zinc oxide $(\mathrm{ZnO})$ is a very tempting material because of the importance of $\mathrm{ZnO}$ in heterogeneous catalysis. Here, first results of the preparation of ordered mesoporous
\end{abstract}

$\mathrm{ZnO}$ materials by using different templates are reported. Porous materials with high surface area, different pore sizes, and nanocrystalline $\mathrm{ZnO}$ walls

Keywords: heterogeneous catalysis liquid crystals $\cdot$ mesoporous materials • precursor chemistry • zinc oxide were obtained. Furthermore, we compare the two fundamental templating techniques, involving liquid crystals or ordered mesoporous carbon materials as templates. Regarding the formation of mesoporous $\mathrm{ZnO}$, it was evident that the hard-matter carbon template is superior.
Zinc oxide $(\mathrm{ZnO})$ is attracting tremendous research interest due to its vast spectrum of properties and applications. $\mathrm{ZnO}$ is an n-type direct band-gap semiconductor with $\Delta E_{\text {gap }}=3.37 \mathrm{eV}$ and an exciton-binding energy of $60 \mathrm{meV}$. Thus, it possesses properties similar to those of gallium nitride, but it is much easier to prepare. Among the interesting features of $\mathrm{ZnO}$ are piezoelectric- and electromechanical-coupling properties, and it has been applied for UVlight-emitting diodes, lasers, in photovoltaic solar cells, in UV-photodetectors, gas-sensors, and for varistors. ${ }^{[1]}$ However, more important for this paper is the pivotal role of $\mathrm{ZnO}$ as a component in industrial methanol-synthesis catalysts $\left(\mathrm{Cu} / \mathrm{ZnO} / \mathrm{Al}_{2} \mathrm{O}_{3}\right){ }^{\left[{ }^{[2]}\right.}$ Methanol is increasing in importance because it is believed to be one key compound in future hydrogen-based energy technologies. ${ }^{[3]}$

Because catalytic activity depends highly on dispersion and surface area, ${ }^{[4]}$ an approach used frequently is to immobilize the respective catalytic system on suitable supports. Ordered mesoporous silica materials, such as MCM-41 or SBA- $15,{ }^{[5,6]}$ have proven to be valuable supports for hetero-

[a] Dr. S. Polarz, A. V. Orlov

Technical University Berlin, Institute of Chemistry

Nanostructured Materials Group, Strasse des 17. Juni 10623 Berlin (Germany)

Fax: (+49)314-22-168

E-mail: sebastian.polarz@tu-berlin.de

[b] Prof. F. Schüth, Dr. A.-H. Lu

Max-Planck-Institut für Kohlenforschung, Kaiser-Wilhelm-Platz 1 45470 Mülheim an der Ruhr (Germany) geneous catalysts, due to their unique nanostructure. ${ }^{[7]} \mathrm{Re}$ cently, we were able to prepare size-selected $\mathrm{ZnO}$ particles in the pores of ordered mesoporous silica materials. ${ }^{[8]}$ The key to success in this preparation was the use of an innovative, organometallic-precursor system resembling $\mathrm{ZnO}$ on a molecular scale..$^{[8,9]}$

Due to the potentially large surface area, the idea is very tempting that the nanoporous material itself is composed of a matrix material that is catalytically more relevant than silica. This approach is still rather unexplored, although some success in the synthesis of non-siliceous, ordered mesoporous materials has been made. ${ }^{[6,10,11]}$ The preparation of some transition-metal oxides, especially $\mathrm{TiO}_{2}$, in a mesoporous state was achieved by using liquid-crystalline templates. $^{[12]}$ A wider spectrum of materials (e.g., mesoporous $\mathrm{MgO}$ ) could be accessed by using a thermally and mechanically more robust template, an ordered mesoporous carbon material. ${ }^{[11,13]}$ Although there have been some efforts to synthesize nanoporous $\mathrm{ZnO}$ with ordered porosity, ${ }^{[14]}$ to the best of our knowledge, the successful preparation of this interesting material has not yet been reported. One of the problems encountered in previous attempts is the reduction of saltlike $\mathrm{ZnO}$ precursor, for instance zinc nitrate, in the course of the thermolytic removal of the template.

Here, we present the successful preparation of ordered mesoporous $\mathrm{ZnO}$ with high surface area. We compared the two methods of preparation, the true liquid-crystal templating and the exotemplating with mesoporous carbons, and obtained $\mathrm{ZnO}$ materials with different pore sizes. In both 
cases we took advantage of the special organometallic single-source precursor system mentioned above. These precursors are characterized by a central " $\mathrm{Zn}_{4} \mathrm{O}_{4}$ " heterocubane core and have the general formula $\left[\left\{\mathrm{CH}_{3} \mathrm{ZnOR}\right\}_{4}\right]$. The organometallic functionalities $\left(\mathrm{Zn}-\mathrm{CH}_{3}\right)$ of the precursors are very important because they enable the preparation of $\mathrm{ZnO}$ in nanocrystalline form, either thermolytically at low temperatures, or hydrolytically [Eq. (1)]:

$$
\begin{aligned}
& {\left[\left\{\mathrm{H}_{3} \mathrm{CZnO}\left(\mathrm{CH}_{2}\right)_{2} \mathrm{OCH}_{3}\right\}_{4}\right]+4 \mathrm{H}_{2} \mathrm{O} \rightarrow} \\
& 4 \mathrm{ZnO}+4 \mathrm{HOCH}_{2} \mathrm{CH}_{2} \mathrm{OCH}_{3}+4 \mathrm{CH}_{4}
\end{aligned}
$$

By conducting either a hydrolytical treatment of the precursor $\left[\left\{\mathrm{CH}_{3} \mathrm{ZnOR}\right\}_{4}\right]$, in which $\mathrm{R}=\left(\mathrm{CH}_{2}\right)_{2} \mathrm{OCH}_{3}$, in a humidity chamber at $T=60^{\circ}$ with a humidity of $50 \%$, or a thermolytical treatment at $T=350{ }^{\circ} \mathrm{C}$ in an atmosphere containing $20 \% \mathrm{O}_{2}$, it is possible to assign the recorded powder $\mathrm{X}$-ray diffractograms (PXRD) to phase-pure $\mathrm{ZnO}$ with wurtzite structure (Figure 1a). The broad reflexes indicate that quite small $\mathrm{ZnO}$ crystallites were formed. Particle sizes $D$ were calculated from the full-width half-maximum (FWHM) of PXRD patterns by using the isolated reflex centered at $2 \theta=56.6^{\circ} \cdot{ }^{[15]}$ For the thermal route, particles had an average diameter of $D_{\text {thermal }}=6.5( \pm 1) \mathrm{nm}$ and for the hydrolytic route, $D_{\text {hydrolytic }}=5.7( \pm 1) \mathrm{nm}$. Next, the organometallic precursor was infiltrated into the ordered mesoporous carbon matrix of the PAN-CMK-3 type. ${ }^{[16-18]}$ Pure carbon CMK-3 was also used, but the templating was found to be superior with the PAN-based material. Concerning the infiltration and $\mathrm{ZnO}$-formation process, the special precursor $\left[\left\{\mathrm{CH}_{3} \mathrm{ZnO}\left(\mathrm{CH}_{2}\right)_{2} \mathrm{OCH}_{3}\right\}_{4}\right]$ used in this report possesses several advantages over alternative saltlike $\mathrm{ZnO}$ precursors, such as zinc nitrate: As well as the $\mathrm{ZnO}$ content being relatively high $(53 \%)$, the pure precursor itself is a liquid. This allows the entire pore volume to be filled with the undiluted precursor (Figure 2). The infiltration of the precursor was monitored by FTIR spectroscopy (Figure 1b), which was, however, hampered by the black color resulting from the carbonaceous support. As the carbon is relatively transparent, spectroscopically, within the fingerprint region, the emergence of the signals at $\tilde{v}=1455,1363,1250,1195,1127$, 1063,1021 , and $894 \mathrm{~cm}^{-1}$ in the meso-carbon precursor composite indicates that $\left[\left\{\mathrm{CH}_{3} \mathrm{ZnO}\left(\mathrm{CH}_{2}\right)_{2} \mathrm{OCH}_{3}\right\}_{4}\right]$ could be infiltrated without decomposition.

To separate the $\mathrm{ZnO}$-formation step from the removal of the carbon matrix, $\left[\left\{\mathrm{CH}_{3} \mathrm{ZnO}\left(\mathrm{CH}_{2}\right)_{2} \mathrm{OCH}_{3}\right\}_{4}\right]$ was first transformed into $\mathrm{ZnO}$ inside the confining reaction field of the CMK material by using the hydrolytic approach at $T=50^{\circ} \mathrm{C}$ with a humidity of $50 \%$. PXRD of the resulting material (Figure 1a) showed that a composite was formed that contains nanocrystalline $\mathrm{ZnO}$. The $\mathrm{ZnO}$ reflexes are very broad, indicating the formation of nanoscaled particles, but due to the limited quality of the data, a distinct determination of the value for the average particle diameter by using the Scherrer Equation is difficult. We assigned the increased scattering intensity at angles below $2 \theta=30^{\circ}$ to the porous carbon matrix. After drying to remove the alcohols released
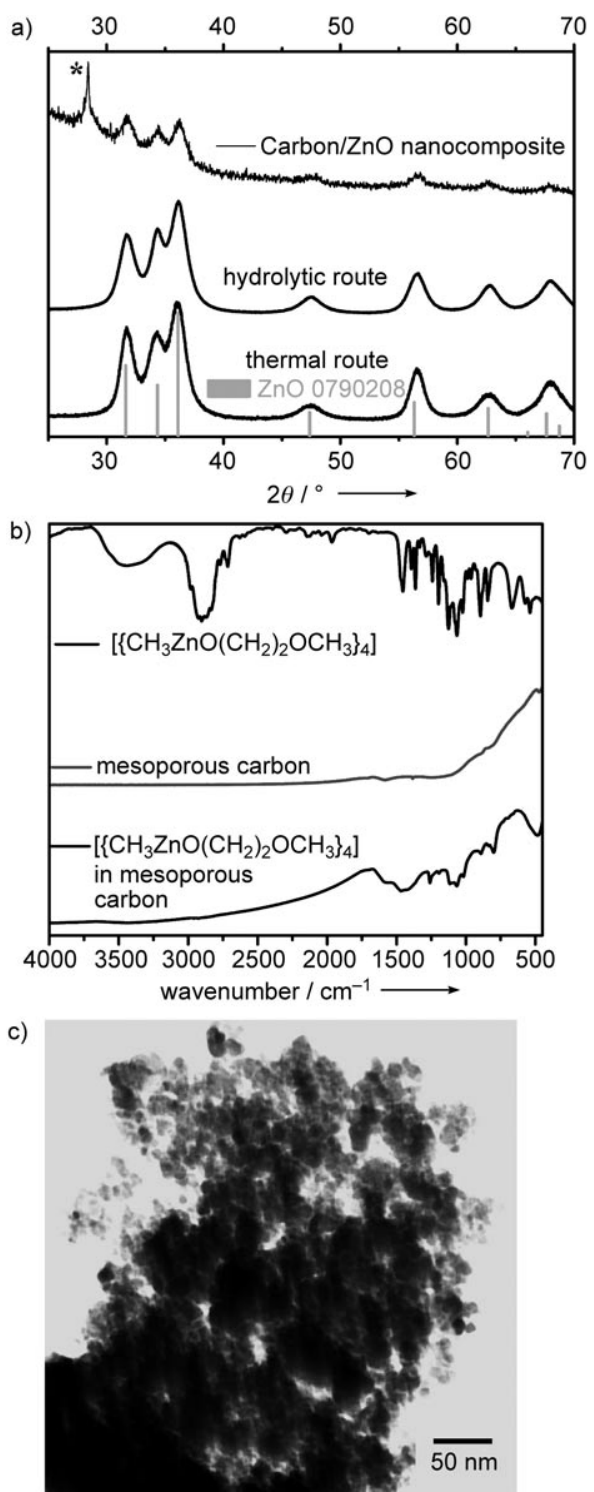

Figure 1. a) PXRD patterns of $\mathrm{ZnO}$ prepared from $\left[\left\{\mathrm{CH}_{3} \mathrm{ZnO}\right.\right.$ $\left.\left.\left(\mathrm{CH}_{2}\right)_{2} \mathrm{OCH}_{3}\right\}_{4}\right]$ by the thermal route $\left(T=350^{\circ} \mathrm{C}\right)$, by the hydrolytic route $\left(T=60^{\circ} \mathrm{C}\right.$, humidity $\left.50 \%\right)$, and of the CMK-3/ZnO composite. The * denotes a reflex originating from the sample holder. b) FTIR spectra of the pure $\mathrm{ZnO}$ precursor (top), the CMK-3 (middle), and the precursor infiltrated into the latter (bottom). c) TEM image of the $\mathrm{ZnO}^{\mathrm{III}}$ material prepared in the absence of a template.

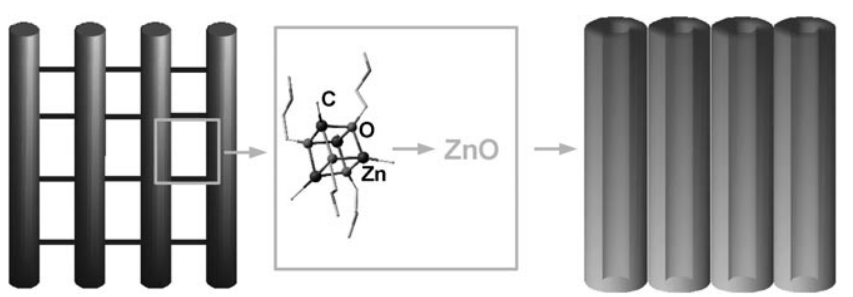

Figure 2. Schematic representation of the preparative approach for ordered mesoporous $\mathrm{ZnO}$ materials. A mesoporous carbon material of the CMK-type ${ }^{[17-19]}$ (left) was infiltrated with the liquid organometallic heterocubane $\left[\left\{\mathrm{CH}_{3} \mathrm{ZnO}\left(\mathrm{CH}_{2}\right)_{2} \mathrm{OCH}_{3}\right\}_{4}\right]$ (molecular structure shown in the middle), which was transformed into $\mathrm{ZnO}$ inside the pores of the carbon. After removal of the template, an ordered mesoporous $\mathrm{ZnO}$ material with nanocrystalline walls was obtained (right). 
due to hydrolysis of the precursor, a material containing $60 \%$ carbon and $40 \% \mathrm{ZnO}$ was obtained, according to elemental analysis.

Finally, the carbon matrix was removed by oxidation in pure oxygen and the process was monitored by thermogravimetric analysis (TGA) (Figure 3). Our experiments indicate that the formation of $\mathrm{ZnO}$ prior to the removal of the

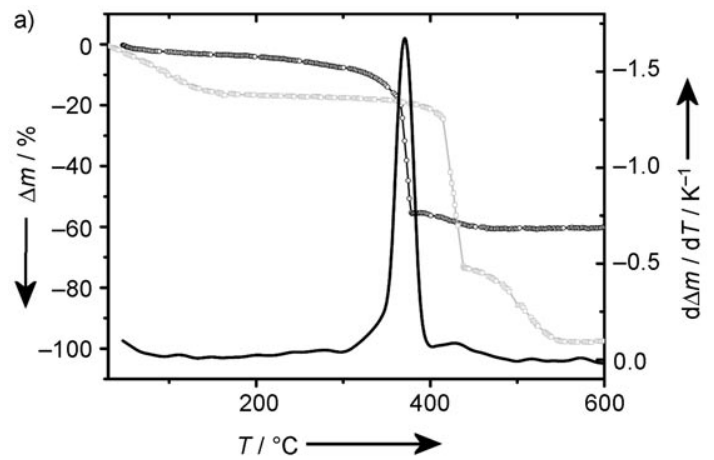

b)

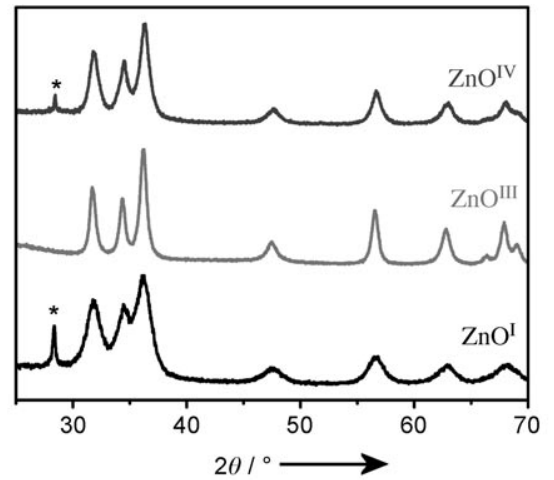

Figure 3. a) TGA traces for the oxidation of the pure mesoporous carbon matrix (grey line) and the CMK-3/ZnO composite (black line). The differential TG curve is shown for the latter material only. b) PXRD patterns of $\mathrm{ZnO}$ materials obtained by using a mesoporous carbon template (bottom), a lyotropic phase as template (top), and in the absence of template (middle) (see also Table 1).

carbon template is essential. The pure mesoporous carbon is very stable, even in a pure- $\mathrm{O}_{2}$ atmosphere, and shows only minor mass loss at temperatures up to $415^{\circ} \mathrm{C}$, followed by two decomposition steps at 426 and $508^{\circ} \mathrm{C}$. However, as soon as $\mathrm{ZnO}$ is present in the pores of the carbon, a mass loss of $59 \%$ is observed at $T=370{ }^{\circ} \mathrm{C}$. This indicates a catalytic effect of $\mathrm{ZnO}$ during the oxidation of carbon, which has also been reported for other carbon materials. ${ }^{[20]}$ Finally, a sample containing $94 \% \mathrm{ZnO}$ and residual carbon was obtained, despite the powder being practically colorless. Therefore, we recorded UV-visible spectra in diffuse reflectance mode, shown in Figure 4. Due to its black color, the mesoporous carbon template is characterized by low reflectivities (high absorption coefficients; see Figure 4a) over the whole spectral region. On the other hand, the mesoporous $\mathrm{ZnO}$ prepared is transparent up to the $\mathrm{UV}$ region $(\approx 3.2 \mathrm{eV})$. However, comparison to a bulk $\mathrm{ZnO}$ as a reference indi-

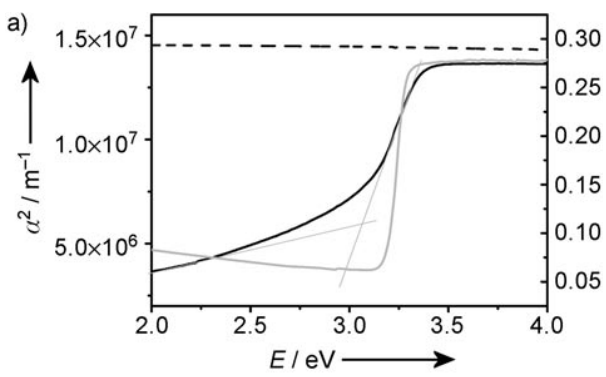

b)

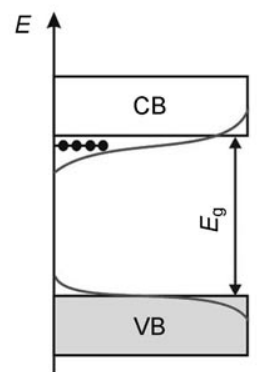

Figure 4. a) UV/Vis spectra of the mesoporous carbon (dashed line), bulk $\mathrm{ZnO}$ as a reference (grey line), and the mesoporous $\mathrm{ZnO}$ (black solid line). b) Model for the band-gap modification through atoms of carbon impurity.

cates that the band edge is significantly red-shifted (Figure 4a) and is smeared out. As we reported previously, such effects can be explained if atoms of impurities, such as carbon, are present in the zinc oxide lattice. ${ }^{[9]}$ Contamination of the mesoporous $\mathrm{ZnO}$ by carbon during the thermal oxidation of the carbon matrix is clearly very difficult to avoid, taking into account the intimate penetration of both matrices (carbon and $\mathrm{ZnO}$ ).

To obtain a first impression of the influence of the thermal treatment on the $\mathrm{ZnO}$, PXRD patterns were recorded. In addition, a reference sample $\mathrm{ZnO}^{\mathrm{III}}$ was prepared (see Experimental Section), in which the $\left[\left\{\mathrm{CH}_{3} \mathrm{ZnO}-\right.\right.$ $\left.\left.\left(\mathrm{CH}_{2}\right)_{2} \mathrm{OCH}_{3}\right\}_{4}\right]$ was treated under analogous conditions, but in absence of template. Analysis of the PXRD data for the PAN-CMK-3 templated sample $\mathrm{ZnO}^{\mathrm{I}}$ by using the WarrenAverbach method (fit not shown) indicated that the average crystalline-domain size is $5.2( \pm 1) \mathrm{nm}$. Comparison of the PXRD patterns and particle sizes prior to the removal of the carbon (Figure 1a) shows that the mesoporous template is clearly very effective in confining the growth of the $\mathrm{ZnO}$ phase. In contrast, the $\mathrm{ZnO}$ material prepared in the absence of template is composed of much larger primary particles $\left(D_{\mathrm{ZnO}}{ }^{\mathrm{III}}=17.3( \pm 1) \mathrm{nm}\right)$. Furthermore, transmission electron micrographs (TEM) of this material reveal that the particles are very polydisperse in size and are randomly agglomerated (Figure 1c). However, the sample prepared by using the CMK-3 template $\left(\mathrm{ZnO}^{\mathrm{I}}\right)$ appears very different, as shown in Figure 5.

Although the pore system does not exhibit very high order, as usually expected for ordered mesoporous materials, the majority of the sample $(\approx 90 \%)$ can be correlated directly to the ordered mesoporous carbon template. Paral- 


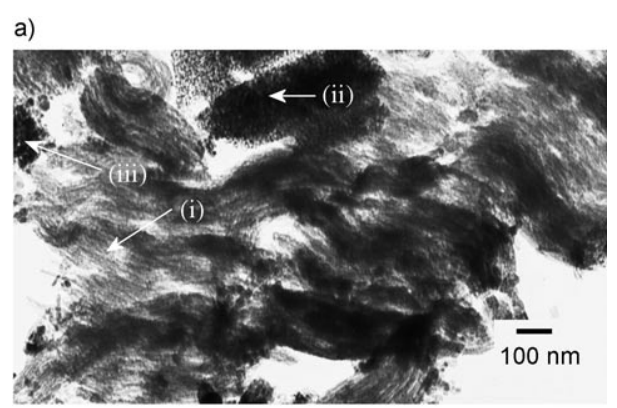

b)

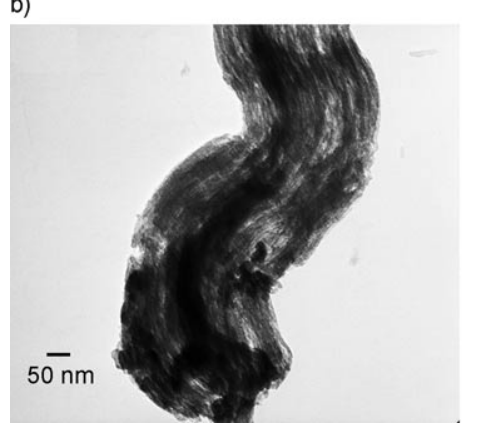

Figure 5. TEM micrographs of the mesoporous $\mathrm{ZnO}^{\mathrm{I}}$ material prepared. a) Overview image indicating ordered mesoporous areas (i), disordered mesoporous areas (ii), and fully disordered areas (iii). b) Higher-magnification image of phase (i).

lel channels with an average width of $7.5 \mathrm{~nm}$ run through the material (position (i) in Figure 5a), and even the characteristic morphology of the particles in the original mesoporous carbon phase is maintained. Even if the structure appears to be less ordered than in the original carbon template, the TEM images give a clear indication that the $\mathrm{ZnO}$ phase was grown predominantly inside the porous carbon phase. Around $7 \%$ of the sample (position (ii) in Figure 5a) exhibits a meso-structure that is more disordered in which the original pore system seems to be destroyed. Nevertheless, the external morphology of the mesoporous particles is retained and the primary particles are very small. Finally, some agglomerates of larger particles were found (position (iii) in Figure 5a) that can be accounted for by the minor fraction of $\mathrm{ZnO}$ that was formed outside the confinement of the mesoporous carbon template.

Notably, for materials applied in heterogeneous catalysis, a high order of the pore system is not important, unlike a high surface area. Therefore, the resulting samples were further investigated by taking $\mathrm{N}_{2}$-physisorption measurements (Figure 6). The ordered PAN-CMK-3 material used as a template is a highly porous material with an average pore size $\left(D_{\mathrm{P}}\right)$ of $3.0 \mathrm{~nm}$ and a BET surface area $\left(S_{\mathrm{BET}}\right)$ of $763 \mathrm{~m}^{2} \mathrm{~g}^{-1}$. The $\mathrm{ZnO}^{\mathrm{I}}$ sample obtained after removal of the carbon template is also characterized by an isotherm typical for mesoporous materials. ${ }^{[21]}$ It possesses an average (BJH) pore size of $6.8 \mathrm{~nm}$, which corresponds rather well to the pore size of the initial SBA-15 used as a template to produce the CMK-3, ${ }^{[16-18]}$ and also to the TEM images. According to a BET evaluation, a material with a surface area of
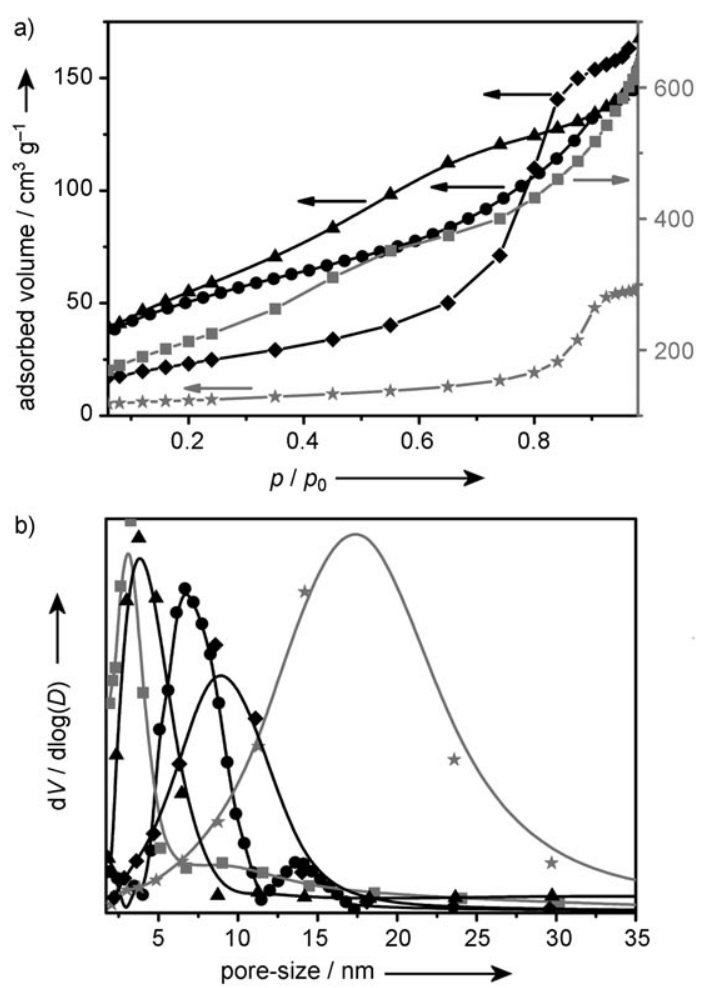

Figure 6. a) Isotherms of the various samples prepared in this study. b) $\mathrm{BJH}$ pore-size distribution functions resulting from evaluation of the adsorption branches. For clarity, only the adsorption branches (except for $\left.\mathrm{ZnO}^{\mathrm{I}}\right)$ are shown. PAN-CMK-3 (๘); $\mathrm{ZnO}^{\mathrm{I}}(\bullet) ; \mathrm{ZnO}^{\mathrm{II}}(\bullet) ; \mathrm{ZnO}^{\mathrm{III}}(\bullet)$; $\mathrm{ZnO}^{\mathrm{IV}}(\star)$.

$192 \mathrm{~m}^{2} \mathrm{~g}^{-1}$ could be obtained. Relative to the mesoporous carbon material or to typical mesoporous silica materials, this latter surface area seems to be quite small. However, due to the higher density of $\mathrm{ZnO}\left(5.6 \mathrm{~g} \mathrm{~cm}^{-3}\right)$ relative to carbon $\left(2.3 \mathrm{~g} \mathrm{~cm}^{-3}\right)$, the mentioned value can be considered as reasonable and high. In addition, the transition of pore size of the template phase to that of the target material is in good agreement with other oxides obtained by a similar method also using ordered mesoporous carbon materials as templates. ${ }^{[13]}$ Regarding the $\mathrm{N}_{2}$-physisorption data, it is also important to note the significant uptake of gas at high pressures (Figure 6a), which can be explained by the interstitial volumes between the mesoporous particles (see Figure 5a).

We also investigated the physisorption behavior of the reference sample $\mathrm{ZnO}^{\mathrm{III}}$ that was prepared in the absence of any template, but under otherwise identical conditions. The reference sample was characterized by a low $S_{\mathrm{BET}}$ of only $24 \mathrm{~m}^{2} \mathrm{~g}^{-1}$ (see Table 1). This correlates well to the formation of larger pores of average diameter $17 \mathrm{~nm}$ accompanied by a much broader pore-size distribution. The latter results clearly emphasize that the ordered mesoporous carbon material acted as a template for the mesoporous $\mathrm{ZnO}^{\mathrm{I}}$ material.

In addition to PAN-CMK-3, we also applied CMK-1 as a template. CMK-1 is prepared by using MCM-48 as the parent silica phase ${ }^{[17]}$ thus, the backtransformation of CMK- 
Table 1. Nanoporous $\mathrm{ZnO}$ materials prepared in this study.

\begin{tabular}{|c|c|c|c|c|}
\hline Sample & Template & $\mathrm{ZnO}$ particle size $[\mathrm{nm}]$ & BET surface area $\left[\mathrm{m}^{2} \mathrm{~g}^{-1}\right]$ & Average pore size $[\mathrm{nm}]$ \\
\hline $\mathrm{ZnO}^{\mathrm{I}}$ & PAN-CMK-3 & 5.2 & 192 & $6.8(\mathrm{FWHM}=3.4)$ \\
\hline $\mathrm{ZnO}^{\mathrm{II}}$ & CMK-1 & n.d. ${ }^{[a]}$ & 202 & $3.8(\mathrm{FWHM}=2.4)$ \\
\hline $\mathrm{ZnO}^{\mathrm{III}}$ & - & 17.3 & 24 & $17.4(\mathrm{FWHM}=8.4)$ \\
\hline $\mathrm{ZnO}^{\mathrm{IV}}$ & liquid crystal & 8.9 & 85 & $8.9(\mathrm{FWHM}=5.0)$ \\
\hline
\end{tabular}

[a] Not determined.

1 to an ordered mesoporous $\mathrm{ZnO}^{\mathrm{II}}$ should lead to pore sizes similar to those for MCM-48. ${ }^{[22]}$ As the BJH pore-size distributions show (see Figure 6b), this is indeed the case, as the average pore size of the resulting mesoporous $\mathrm{ZnO}$ material is $3.8 \mathrm{~nm}$, although the distribution is somewhat broader than in the case of siliceous MCM materials. The use of CMK-1 as a template allows the surface area of the resulting nanoporous $\mathrm{ZnO}^{\mathrm{II}}$ material to increase even further to $202 \mathrm{~m}^{2} \mathrm{~g}^{-1}$ (BET).

Finally, we attempted to prepare an ordered mesoporous $\mathrm{ZnO}^{\mathrm{IV}}$ material directly by performing true liquid-crystal templating of a triblock copolymer poly(ethylene oxide)poly(propylene oxide)-poly(ethylene oxide) (PEO-PPOPEO) (pluronic; for details, see Experimental Section). Prior to removal of the template phase, but after the formation of $\mathrm{ZnO}$, solid, monolithic particles that were optically fully transparent were obtained, as can be seen from microscope images (Figure 7a). The texture apparent in the polar- present, the material is characterized by a meso-, but random, pore system. This observation is also in agreement with the PXRD data recorded for sample $\mathrm{ZnO}^{\mathrm{IV}}$. Although the $\mathrm{ZnO}$ reflexes are broader than for the sample prepared in the absence of template, they are significantly narrower than for sample $\mathrm{ZnO}^{\mathrm{I}}$ (Figure 3b). According to the Scherrer Equation, $\mathrm{ZnO}^{\mathrm{IV}}$ is composed of particles $\approx 8.9 \mathrm{~nm}$ in size. However, the block-copolymer template clearly has a certain effect, as a reference experiment in the absence of the liquid crystal shows. Under otherwise identical conditions, $\mathrm{ZnO}$ with a BET surface area of only $28 \mathrm{~m}^{2} \mathrm{~g}^{-1}$ and an extremely broad pore-size distribution centered at $15 \mathrm{~nm}$ was found (data not shown).

Therefore, concerning the preparation of mesoporous $\mathrm{ZnO}$ materials, the hard-matter CMK templates appear to be superior to the soft-matter liquid crystals. Nevertheless, the preparation routes presented in this paper and summarized in Table 1 allow the preparation of mesoporous $\mathrm{ZnO}$ materials with nanocrystalline walls (Figure 3) and different pore sizes. Studies of the application of this material in the methanol-synthesis reaction are underway.

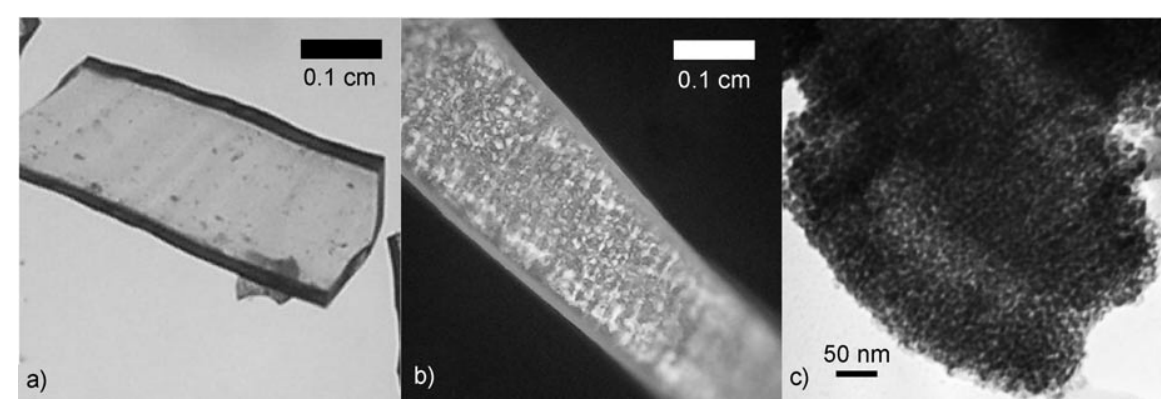

Figure 7. Microscope images of the $\mathrm{ZnO}$ /liquid-crystal composite under normal light (a) and between crossed polarizers (b). c) TEM image of the liquid-crystal templated $\mathrm{ZnO}^{\mathrm{IV}}$ after removal of the template.

\section{Experimental Section}

CMK templating: The ordered mesoporous nitrogen-containing carbon material was prepared according to reported procedures. ${ }^{[16-18]}$ The liquid ZnO-precursor $\quad\left[\left\{\mathrm{H}_{3} \mathrm{CZnO}\right.\right.$ $\left.\left.\left(\mathrm{CH}_{2}\right)_{2} \mathrm{OCH}_{3}\right\}_{4}\right]$ was prepared according to the literature. ${ }^{[8]}$ The infiltration experiments were performed under exclusion of air and moisture by using Schlenk techniques, and the mesoporous carbon was carefully dried prior to use. Typically, $0.3 \mathrm{~g}$ of the mesoporous carbon powder was stratified with the liquid and undiluted $\left[\left\{\mathrm{H}_{3} \mathrm{CZnO}\right.\right.$ $\left.\left.\left(\mathrm{CH}_{2}\right)_{2} \mathrm{OCH}_{3}\right\}_{4}\right]$. To facilitate the infiltration process, vacuum was applied over a period of $5 \mathrm{~h}$. The resulting material was filtrated by using a reversal frit and was then washed twice with dry toluene. The resulting black powder was transferred into a humidity chamber and treated for $24 \mathrm{~h}$ at a relative humidity of $50 \%$ and $T=50^{\circ} \mathrm{C}$. The sample was then transferred into either a tube oven or into the TG instrument. Oxidation of the sample was achieved in pure oxygen with a heating rate of $5 \mathrm{Kmin}^{-1}$. To remove the carbon matrix, the sample was kept at a final temperature of $370^{\circ} \mathrm{C}$ for $30 \mathrm{~min}$.

Liquid-crystal templating: Liquid cubane $(1 \mathrm{~mL})$ was added to previously dried triblock copolymer $(\mathrm{PEO})_{106}(\mathrm{PPO})_{70}(\mathrm{PEO})_{106}(0.5 \mathrm{~g})$ (Aldrich). The mixture was heated to $80^{\circ} \mathrm{C}$ and stirred for $15 \mathrm{~min}$ to form a solution that became waxy at RT. An amount of this substance $(0.15 \mathrm{mg})$ was dissolved in THF $(0.5 \mathrm{~mL})$, poured into a Petri dish, and transferred into a humidity chamber set to a humidity of $50 \%$ and $50^{\circ} \mathrm{C}$. The sample was kept for 15 min under these conditions. Removal of the template was achieved by calcination in air at $370^{\circ} \mathrm{C}$ for $30 \mathrm{~min}$.

Analytical techniques: Thermogravimetric analysis (TGA) of the precursor was conducted by using a thermogravimetric setup from Rubotherm. 
X-ray diffractograms were recorded by using a Bruker AXS D8 Advance instrument with $\mathrm{Cu}_{\mathrm{K} \alpha}$ radiation $(\lambda=1.5418 \AA)$, and a position-sensitivedetector (PSD) diffractometer using $\mathrm{CuK}_{\alpha}$ radiation in the $2 \theta$ range from 25 to $85^{\circ}$ with steps of $0.015^{\circ}$. Crystallite size and microstrain parameters were determined by performing a full-profile Warren-Averbach fit of experimental XRD patterns with subsequent decomposition of reflection profiles into Gaussian and Lorenzian parts, taking into account instrumental contribution to peak broadening. Conventional transmission electron microscopy (CTEM) was performed by using a JEOL JSEM 200B microscope. FTIR spectra were recorded from $\mathrm{KBr}$ pellets by using a Bruker Vector 22 spectrometer. $\mathrm{N}_{2}$-physisorption measurements were recorded by using a Micromeritics Gemini.

\section{Acknowledgements}

S.P. acknowledges the Deutsche Forschungsgemeinschaft (DFG) for financial support (Emmy-Noether scholarship) and Prof. Dr. M. Driess for his generous support. Dr. R. Liedke is acknowledged for making TEM measurements.

[1] C. Kligshirn, Phys. Status Solidi B 1975, 71, 547; D. C. Look, Mater. Sci. Eng. B 2001, 80, 383; Hickerne, IEEE Trans. Microwave Theory Tech. 1969, 17, 957; D. C. Look, B. Claftin, Phys. Status Solidi B 2004, 241, 624; B. K. Meyer, H. Alves, D. M. Hofmann, W. Kriegseis, D. Forster, F. Bertram, J. Christen, A. Hoffmann, M. Strassburg, M. Dworzak, U. Haboeck, A. V. Rodina, Phys. Status Solidi B 2004, 241, 231; M. A. Martinez, J. Herrero, M. T. Gutierrez, Sol. Energy Mater. Sol. Cells 1997, 45, 75; N. A. Anderson, X. Ai, T. Q. Lian, J. Phys. Chem. B 2003, 107, 14414; K. Keis, J. Lindgren, S. E. Lindquist, A. Hagfeldt, Langmuir 2000, 16, 4688; E. Monroy, F. Omnes, F. Calle, Semicond. Sci. Technol. 2003, 18, R33; D. R. Clarke, J. Am. Ceram. Soc. 1999, 82, 485.

[2] H. H. Kung, Catal. Rev. Sci. Eng. 1980, 22, 235; K. Klier, Adv. Catal. 1982, 31, 243; H. Wilmer, M. Kurtz, K. V. Klementiev, O. P. Tkachenko, W. Grünert, O. Hinrichsen, A. Birkner, S. Rabe, K. Merz, M. Driess, C. Wöll, M. Muhler, Phys. Chem. Chem. Phys. 2003, 5, 4736.

[3] C. S. Song, Catal. Today 2002, 77, 17.

[4] N. Pernicone, Cattech 2003, 7, 196.
[5] C. T. Kresge, M. Leonowicz, W. J. Roth, J. C. Vartuli, J. S. Beck, Nature 1992, 359, 710; D. Zhao, J. Feng, Q. Huo, N. Melosh, G. H. Fredrickson, B. F. Chmelka, G. D. Stucky, Science 1998, 279, 548.

[6] S. Polarz, B. Smarsly, J. Nanosci. Nanotechnol. 2003, 2, 581.

[7] A. Corma, Chem. Rev. 1997, 97, 2373.

[8] S. Polarz, F. Neues, M. Van den Berg, W. Grünert, L. Khodeir, J. Am. Chem. Soc. 2005, 127, 12028.

[9] V. Ischenko, S. Polarz, D. Grote, V. Stavarache, K. Fink, M. Driess, Adv. Funct. Mater. 2005, 15, 1945; S. Polarz, A. Roy, M. Merz, S. Halm, D. Schröder, L. Scheider, G. Bacher, F. E. Kruis, M. Driess, Small 2005, 1, 540; A. Roy, S. Polarz, S. Rabe, B. Rellinghaus, H. Zähres, F. E. Kruis, M. Driess, Chem. Eur. J. 2004, 10, 1565.

[10] F. Schüth, Chem. Mater. 2001, 13, 3184.

[11] F. Schüth, Angew. Chem. 2003, 115, 3730; Angew. Chem. Int. Ed. 2003, 42, 3604

[12] P. Yang, D. Zhao, D. I. Margolese, B. F. Chmelka, G. D. Stucky, Nature 1998, 396, 152; D. Grosso, G. Soler-Illia, F. Babonneau, C. Sanchez, P. A. Albouy, A. Brunet-Bruneau, A. R. Balkenende, Adv. Mater. 2001, 13, 1085; T. Brezesinski, M. Groenewolt, M. Antonietti, B. Smarsly, Angew. Chem. 2006, 118, 795; Angew. Chem. Int. Ed. 2006, $45,781$.

[13] J. Roggenbuck, M. Tiemann, J. Am. Chem. Soc. 2005, 127, 1096.

[14] J. Jiu, K. Kurumada, M. Tanigaki, Mater. Chem. Phys. 2003, 81, 93; G. H. Ning, X. P. Zhao, J. Li, C. Q. Zhang, Opt. Mater. 2006, 28, 385.

[15] E. Lifshin, X-ray Characterization of Materials, Wiley-VCH, Weinheim, 1999.

[16] A. H. Lu, A. Kiefer, W. Schmidt, F. Schuth, Chem. Mater. 2004, 16, 100

[17] R. Ryoo, S. H. Joo, S. Jun, J. Phys. Chem. B 1999, 103, 7743.

[18] S. Jun, S. H. Joo, R. Ryoo, M. Kruk, M. Jaroniec, Z. Liu, T. Ohsuna, O. Terasaki, J. Am. Chem. Soc. 2000, 122, 10712; R. Ryoo, S. H. Joo, M. Kruk, M. Jaroniec, Adv. Mater. 2001, 13, 677.

[19] H. J. Shin, R. Ryoo, M. Kruk, M. Jaroniec, Chem. Commun. 2001, 349.

[20] A. N. Pushkin, A. A. Lushov, O. K. Gulish, A. P. Rudenko, O. V. Boltalina, A. M. Kharlanov, A. I. Boltalin, T. Y. Glazunova, Russ. J. Phys. Chem. 2005, 79, 557.

[21] M. Thommes, R. Köhn, M. Fröba, J. Phys. Chem. B 2000, 104, 7932.

[22] V. Alfredsson, M. W. Anderson, Chem. Mater. 1996, 8, 1141; M. W. Anderson, Zeolites 1997, 19, 220. 